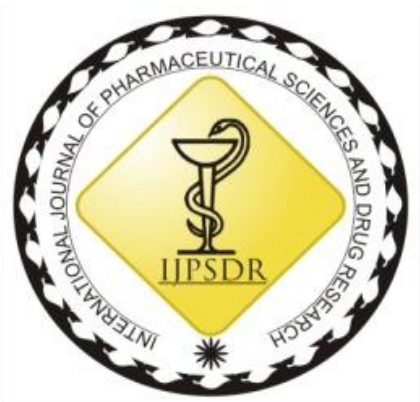

ISSN: 0975-248X

RESEARCH ARTICLE CODEN (USA): IJPSPP

$(\mathrm{cc})$ EY-NG-SA

\title{
Development and Evaluation of Lapatinib Solid Lipid Nanoparticles in the Management of Breast Cancer
}

\author{
Pamu Sandhya* \\ Department of Pharmaceutics, Shadan Women's College of Pharmacy, Khairatabad, Hyderabad-500004, \\ Telangana, India
}

Copyright (c) 2019 Pamu Sandhya. This is an open access article distributed under the terms of the Creative Commons AttributionNonCommercial-ShareAlike 4.0 International License which allows others to remix, tweak, and build upon the work non-commercially, as long as the author is credited and the new creations are licensed under the identical terms.

\begin{abstract}
The current research was aimed at formulation of Lapatinib loaded solid lipid nanoparticles (SLNs) followed by evaluation for effective treatment of breast cancer. The formulations prepared by homogenization and ultrasonication and evaluated for zeta potential, particle size, polydispersity index, entrapment efficiency and invitro dissolution studies. Entrapment efficiency studies indicated proportional relation between concentration of lipid and the amount of drug entrapped. The physicochemical parameter evaluation data indicated $94.27 \%$ entrapment efficiency, $130 \mathrm{~nm}$ particle size and -19.9 zeta potential for stable formulation. The in vitro drug dissolution studies indicated that Lapatinib loaded SLNs (F6) formulated with Dynasan 116 and Egg Lecithin was suitable for anti-cancer therapy with higher drug dissolution rate.
\end{abstract}

Keywords: Lapatinib, SLNs, Solubility, Breast cancer, Dynasan, Egg lecithin.

DOI: 10.25004/IJPSDR.2019.110515

Int. J. Pharm. Sci. Drug Res. 2019; 11(5): 245-249

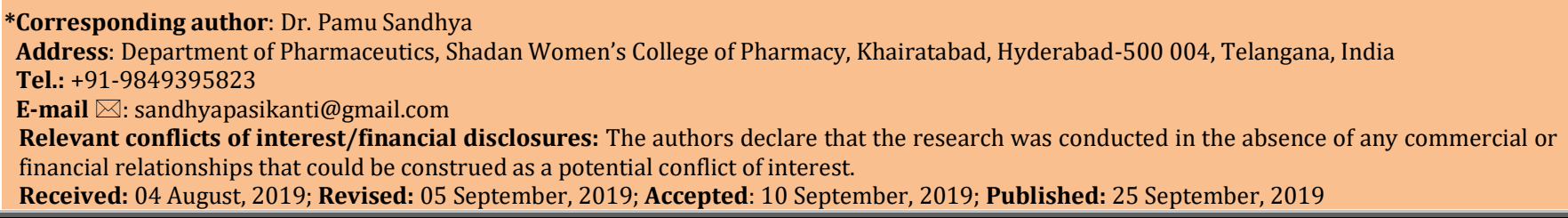

\section{INTRODUCTION}

Despite of administration by the oral route remains most popular method of drug delivery, significant problems arise due to varying physical, chemical or biological characteristics of drug. Improper solubility, instability in gastrointestinal tract, poor membrane permeability or first pass effect is some of the major hurdles that lead to non-acceptance of drug entities with potentiality. ${ }^{[1]}$ The drug delivery systems based on lipids are means of by-passing few physical and chemical hurdles related to drugs that exhibit poor absorption profile from GIT. These potential systems include the more conventional forms of emulsions and micro emulsions, as well as more recent ones like liposomes, microspheres and solid lipid nanoparticles (SLN). ${ }^{[2]}$ SLNs are a type of drug carriers colloidal in nature that had their development in last decade as substitute for present established carriers like emulsions, micro emulsions, liposomes etc. Distinctive properties like large surface area resulting from decreased particle size and high drug entrapment make SLN an appealing option to enhance pharmaceuticals activity. ${ }^{[3]}$ Enhancement of drug absorption by SLN is due to different types of core lipids that mimic 
formation of chylomicrons, which guides the carrier and drug entrapped within to follow transcellular pathway of absorption. [4] SLN enhances the bioavailability of lipophilic drugs by increasing the oral absorption of these drugs. [5]

Lapatinib acts as tyrosine kinase inhibitor that checks the growth of EGFR/ErbB1 and HER2/ErbB2 epidermal growth factors. [6] Lapatinib in combination with capecitabine was first approved by USFDA in 2007 for treatment of breast cancer in metastatic and advanced patients. ${ }^{[7-9]}$

\section{METERIALS AND METHODS \\ Materials}

Lapatinib received as gift sample from Aurobindo Pharma Ltd., Hyderabad. The triglycerides Dynasan 112 and 116 were gifted by Sasol, Germany. Poloxamer188 procured from Fizmerk Chemicals, UP., INDIA. Egg Lecithin (Lipoid E80) was obtained from Lipoid, Germany. The reagents and solvents were of analytical reagent $(\mathrm{AR})$ grade.

Preparation of Lapatinib solid lipid nanoparticles Lapatinib (drug $10 \mathrm{mg}$ ), solid lipid (50/100 mg) and egg lecithin $(100 \mathrm{mg})$ were mixed with $10 \mathrm{~mL}$ of methanol and chloroform (1:1) followed by complete removal of organic solvents by employing a Rota evaporator. The contents heated to a temperature of $5^{\circ} \mathrm{C}$ higher than melting point of the lipid to melt model drug-embedded lipid layer. Poloxamer 188 dissolved in water was heated to similar temperature of oil phase. The hot aqueous phase mixed with the oil phase, followed by homogenization for $4 \mathrm{~min}$ at a rate of $12,000 \mathrm{rpm}$. Sonication (12T-probe) was then performed for 20 minutes to obtained hot emulsion of oil-in-water. Lapatinib loaded solid lipid nanoparticles obtained by subsequently cooling the nanoemulsion to room temperatures.

\section{Measurement of entrapment efficiency}

Entrapment efficiency determined by the chromatographic estimation of free drug in aqueous phase separated from oil phase by ultra-filtration technique. The equipment fitted with centrisart tubes (Sartorius, USA) that contain a sample recovery chamber whose base is fitted with a filtration membrane (M. Wt. 20,000 Da). [10]

Estimation of total drug content

An equimolar mixture of carbinol and chloroform used to dissolve $100 \mu \mathrm{L}$ of the SLN formulation followed by dilutions mobile phase which were then estimated for Lapatinib present by HPLC.

\section{In vitro drug dissolution studies}

Dialysis bag method was employed for in-vitro drug dissolution studies. The membrane used for dialysis (pore size $2.4 \mathrm{~nm}$; molecular weight 12,000-14,000 Da) was soaked in distilled water overnight prior to use and $0.1 \mathrm{~N}$ Hydrochloric acid with $2 \%$ polysorbate 80 was used as dissolution medium. About $1 \mathrm{~mL}$ sample was withdrawn from receiver compartment at predefined intervals of $00.25,0.5,1,2,3,4,6,8,10,12$ and 24 hour time points simultaneously replacing it with equal quantity of release medium. These samples analyzed for drug concentration using UV-Visible Spectrophotometer at $260 \mathrm{~nm}$ after proper dilutions. [11] Characterization

Fourier Transform infrared Spectroscopy FTIR

FTIR studies performed using Shimadzu spectrometer (Japan). Samples were prepared as $\mathrm{KBr}$ pellets

Differential Scanning Calorimetry (DSC)

The DSC chromatogram was recorded by placing accurately weighed $10 \mathrm{mg}$ sample on aluminum plate and increasing the temperature of pan at rate $10^{\circ} \mathrm{C} / \mathrm{min}$ Surface Morphology

The formulation was vacuum dried to thin film after being transferred to a spherical aluminum plate followed by observation under scanning electron microscope (Quantum 200E Instrument). [12]

Determination of Zeta Potential, Particle Size and PDI of SLNs

Malvern Zeta seizer was used to measure zeta potential, size of the particle and polydispersity index (PDI) of Lapatinib loaded SLN's (Nano ZS90). About $100 \mu \mathrm{L}$ of prepared SLN's was mixed with $5 \mathrm{~mL}$ water to obtain measurement of 50-200 Kilo Counts per Second (KCPS). [13]

\section{Stability Studies}

The stability Lapatinib SLNs checked at room temperature and $4^{\circ} \mathrm{C}$ for 60 days followed by determination of particle size, polydispersity index and zeta potential.

\begin{tabular}{|c|c|c|c|c|c|c|}
\hline \multirow{2}{*}{ Ingredient } & \multicolumn{6}{|c|}{ Formulation code } \\
\hline & F 1 & F 2 & F 3 & F 4 & F 5 & F 6 \\
\hline \multicolumn{7}{|c|}{ Organic Phase } \\
\hline Lapatinib & $10 \mathrm{mg}$ & $10 \mathrm{mg}$ & $10 \mathrm{mg}$ & $10 \mathrm{mg}$ & $10 \mathrm{mg}$ & $10 \mathrm{mg}$ \\
\hline Dynasan-112 & $50 \mathrm{mg}$ & $100 \mathrm{mg}$ & $150 \mathrm{mg}$ & - & - & - \\
\hline Dynasan-116 & - & - & - & $50 \mathrm{mg}$ & $100 \mathrm{mg}$ & $150 \mathrm{mg}$ \\
\hline Egg lecithin & $100 \mathrm{mg}$ & $100 \mathrm{mg}$ & $100 \mathrm{mg}$ & $100 \mathrm{mg}$ & $100 \mathrm{mg}$ & $100 \mathrm{mg}$ \\
\hline $\begin{array}{l}\text { Chloroform: } \\
\text { Methanol (1:1) }\end{array}$ & $10 \mathrm{ml}$ & $10 \mathrm{ml}$ & $10 \mathrm{ml}$ & $10 \mathrm{ml}$ & $10 \mathrm{ml}$ & $10 \mathrm{ml}$ \\
\hline \multicolumn{7}{|c|}{ Aqueous Phase } \\
\hline Poloxamer-188 & $10 \mathrm{ml}$ & $10 \mathrm{ml}$ & $10 \mathrm{ml}$ & $10 \mathrm{ml}$ & $10 \mathrm{ml}$ & $10 \mathrm{ml}$ \\
\hline water & $10 \mathrm{ml}$ & $10 \mathrm{ml}$ & $10 \mathrm{ml}$ & $10 \mathrm{ml}$ & $10 \mathrm{ml}$ & $10 \mathrm{ml}$ \\
\hline
\end{tabular}

\section{RESULTS AND DISCUSSION}

Optimization of Process Parameters

Homogenization time

A homogenization time of 5 minutes yielded optimal particle size and PDI. No considerable effect was observed when homogenization time was further increased.

\section{Ultrsonication time}

An Ultrsonication time of $20 \mathrm{~min}$ yielded optimal particle size and PDI.

\section{Lipid concentration}

Lipid concentration was optimized to $100 \mathrm{mg}$ in increasing trend in particle size that slowed drug release was observed when lipid concentration was increased beyond $200 \mathrm{mg}$.

\section{Surfactant concentration}

The optimized concentration of egg lecithin was $100 \mathrm{mg}$ and Poloxamer was $1.5 \% \mathrm{w} / \mathrm{v}$. 




Fig. 1: FTIR Spectrum of Pure Drug of Lapatinib

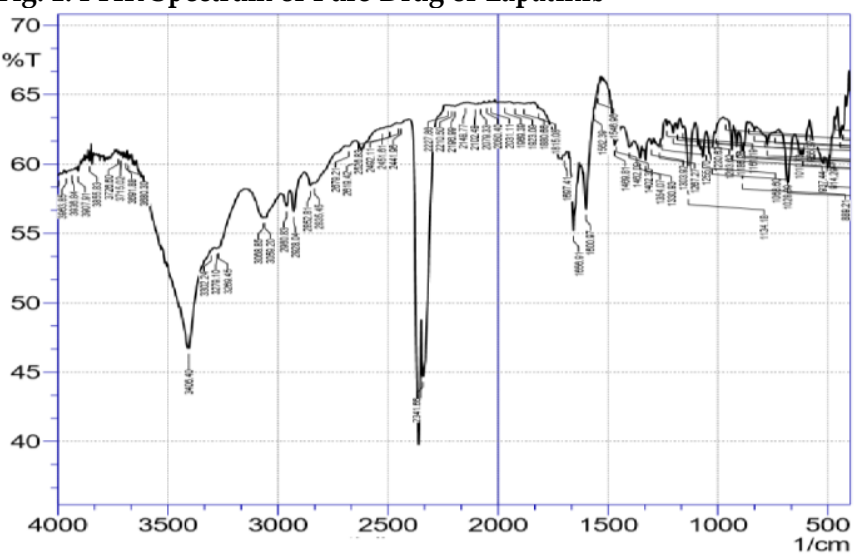

Fig. 2: FTIR Spectrum of SLN loaded Lapatinib

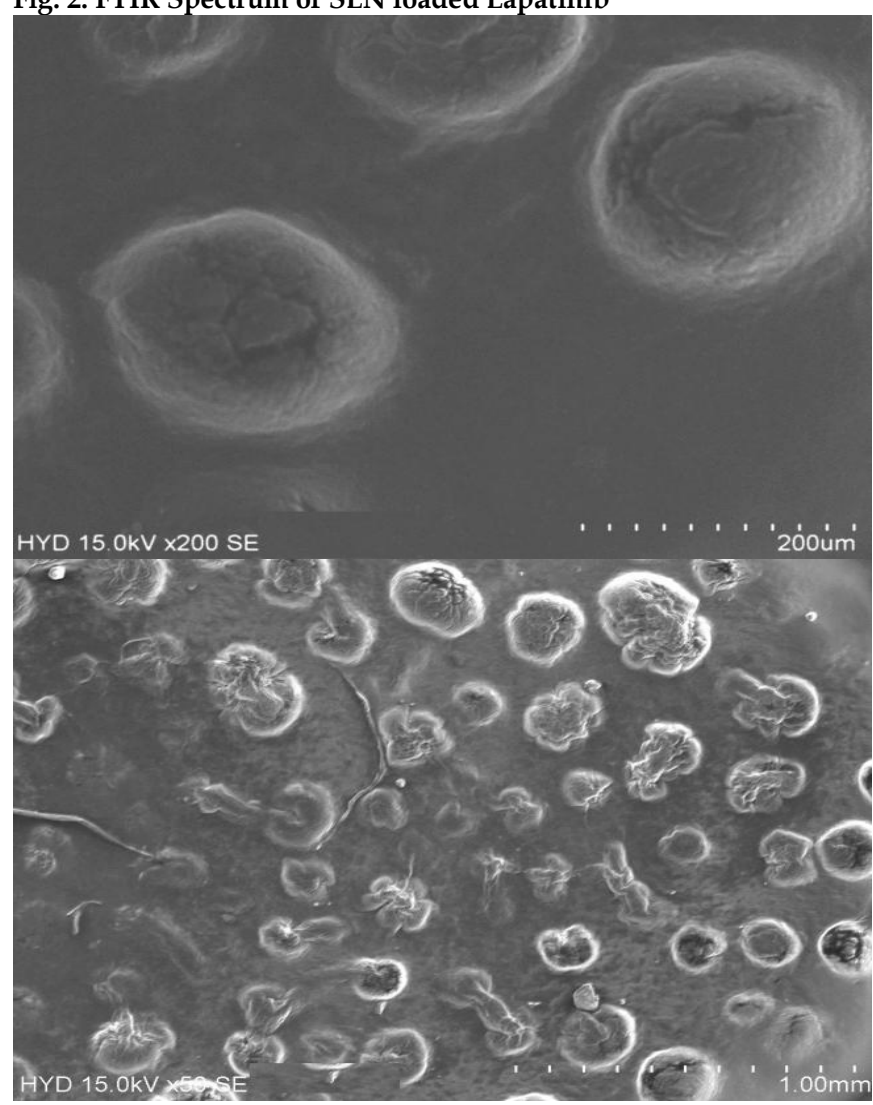

Fig. 3: SEM of Optimized formulation F6 Lapatinib SLN.

\section{Effect of lipid concentration on entrapment efficiency} (EE)

Entrapment efficiency (EE) was one of the important parameter and to attain optimum efficiency the factors like type of lipid, its concentration and type of surfactant were considered. The EE of Solid lipid nanoparticles loaded Dynasan-112 and Dynasan-116 indicated an increase in EE with increase in lipid ratio. Results are tabulated and represented in Table 2. All formulations exhibited good entrapment efficiency that ranged from $88.39 \%$ to $94.27 \%$ with $\mathrm{F} 6$ formulation showing best entrapment efficiency.

\begin{tabular}{ccc} 
Table 2: Entrapment efficiency and total drug content of SLNs $(\mathbf{n}=3)$ \\
\hline Formulation code & $\begin{array}{c}\text { Drug content } \mathbf{( m g )} \\
\mathbf{\pm} \text { SD }\end{array}$ & $\begin{array}{c}\text { Entrapment efficiency } \\
(\mathbf{\%}) \pm \text { SD }\end{array}$ \\
\hline F1 & $9.537 \pm 0.022$ & $88.39 \pm 0.115$ \\
F2 & $9.149 \pm 0.042$ & $92.35 \pm 0.248$ \\
F3 & $9.459 \pm 0.016$ & $90.27 \pm 0.311$ \\
F4 & $9.349 \pm 0.020$ & $91.27 \pm 0.049$ \\
F5 & $9.022 \pm 0.006$ & $92.34 \pm 0.211$ \\
F6 & $9.891 \pm 0.048$ & $94.27 \pm 0.222$ \\
\hline
\end{tabular}

\section{Estimation of drug content}

The maximum drug content of $09.891 \mathrm{mg}$ was observed in formulation F6. The drug content of all prepared formulations is within $9.022-9.891 \mathrm{mg}$ (Table 2).

The drug release from SLNs and suspension by dialysis method

The in vitro drug dissolution studies of Lapatinib SLN formulations were determined by Dialysis bag diffusion technique. Lapatinib-loaded SLN dispersions containing equivalent amount of drug was sealed in dialysis bag. The dialysis bag suspended in $250 \mathrm{~mL}$ of $0.1 \mathrm{~N}$ Hydrochloric acid with $2 \%$ polysorbate 80 and stirred at $50 \mathrm{rpm}$ at $37^{\circ} \mathrm{C} \pm 0.5^{\circ} \mathrm{C}$. The cumulative percent release was more initially during the first hour for pure drug and gradually the drug release was low when compared with other formulations and cumulative release of $97.49 \pm 5.02 \%$ was noted for F6 formulation which was highest of all formulations and pure drug.

Characterization of prepared Lapatinib solid lipid nanoparticles

The presence of characteristic absorption bands of Lapatinib and the optimized SLNs containing Lapatinib suggest no interaction between the drug and excipients (Figure 1 and 2).

Drug-excipients compatibility study by DSC

DSC chromatograms of drug, excipients and drugexcipients mixtures (Figure 3) show thermograms of Lapatinib, Dynasan-112 and Dynasan-116 and the DSC thermograms of Lapatinib exhibits a sharp endothermic peak at $178.60^{\circ} \mathrm{C}$

\section{Scanning Electron Microscopy}

The SEM micrograph indicates rod and spherical shape particles with smooth surface (Figure 4).

Zeta potential and Particle size of prepared SLNs

The particle size of SLNs determines the rate of drug release and drug absorption. Moreover smaller the particle size, larger is interfacial surface area hence improved bioavailability. The particle size of prepared SLN formulations ranged between $88.69 \mathrm{~nm}$ and 130.1 nm. 
Pamu Sandhya et al. / Development and Evaluation of Lapatinib Solid Lipid Nanoparticles.

Table 3: In vitro dissolution studies of Lapatinib loaded SLNs (F1 to F6)

\begin{tabular}{|c|c|c|c|c|c|c|c|}
\hline \multirow{2}{*}{$\begin{array}{c}\text { Time } \\
\text { (h) }\end{array}$} & & \multicolumn{6}{|c|}{ Formulation Code F1 to F6 } \\
\hline & Pure drug & F1 & F2 & F3 & F4 & F5 & F6 \\
\hline 0 & 0 & 0 & 0 & 0 & 0 & 0 & 0 \\
\hline 1 & $55.22 \pm 0.04$ & $8.29 \pm 0.26$ & $10.27 \pm 0.80$ & $12.24 \pm 0.85$ & $13.36 \pm 0.87$ & $15.38 \pm 0.95$ & $16.89 \pm 0.94$ \\
\hline 2 & $61.75 \pm 0.45$ & $12.37 \pm 0.40$ & $14.27 \pm 0.86$ & $18.27 \pm 0.99$ & $22.13 \pm 1.04$ & $24.18 \pm 1.09$ & $26.58 \pm 1.09$ \\
\hline 4 & $69.75 \pm 0.22$ & $16.34 \pm 0.16$ & $21.28 \pm 1.02$ & $26.36 \pm 1.20$ & $30.45 \pm 1.72$ & $32.46 \pm 1.98$ & $35.18 \pm 1.99$ \\
\hline 6 & $70.64 \pm 1.45$ & $25.17 \pm 0.22$ & $27.28 \pm 1.20$ & $34.45 \pm 2.01$ & $38.39 \pm 2.04$ & $40.32 \pm 2.32$ & $43.36 \pm 2.36$ \\
\hline 8 & $71.22 \pm 1.88$ & $30.25 \pm 1.75$ & $32.36 \pm 1.98$ & $42.18 \pm 2.32$ & $45.78 \pm 2.74$ & $46.12 \pm 2.35$ & $49.39 \pm 2.98$ \\
\hline 12 & $73.34 \pm 2.01$ & $39.27 \pm 1.85$ & $43.22 \pm 2.32$ & $51.39 \pm 2.98$ & $55.47 \pm 2.45$ & $58.32 \pm 2.98$ & $60.49 \pm 3.26$ \\
\hline 16 & $75.53 \pm 2.41$ & $52.34 \pm 1.42$ & $53.28 \pm 2.98$ & $60.49 \pm 3.18$ & $63.26 \pm 3.19$ & $65.98 \pm 3.20$ & $69.39 \pm 4.11$ \\
\hline 20 & $77.01 \pm 2.78$ & $60.47 \pm 2.33$ & $62.14 \pm 3.18$ & $70.39 \pm 4.02$ & $75.36 \pm 4.80$ & $79.45 \pm 4.05$ & $84.45 \pm 4.83$ \\
\hline 24 & $80.19 \pm 2.99$ & $90.37 \pm 2.42$ & $93.45 \pm 4.98$ & $92.80 \pm 5.01$ & $94.27 \pm 5.00$ & $95.45 \pm 5.01$ & $97.49 \pm 5.02$ \\
\hline
\end{tabular}

Table 4: Stability studies of the optimized formulation (F6) at both $25^{\circ} \mathrm{C}$ and $4^{\circ} \mathrm{C}$ for 60 days

\begin{tabular}{|c|c|c|c|c|c|c|}
\hline \multirow{2}{*}{ Day } & \multicolumn{3}{|c|}{$25^{\circ} \mathrm{C}$} & \multicolumn{3}{|c|}{$4^{\circ} \mathrm{C}$} \\
\hline & Size (nm) & PDI & Zeta potential (mV) & Size (nm) & PDI & Zeta potential (mV) \\
\hline 1 & $88.69 \pm 1.45$ & $0.517 \pm 0.045$ & $-22.9 \pm 1.10$ & $88.69 \pm 1.58$ & $0.517 \pm 0.017$ & $-22.9 \pm 1.10$ \\
\hline 30 & $102.24 \pm 5.27$ & $0.521 \pm 0.152$ & $-21.24 \pm 2.06$ & $99.27 \pm 2.84$ & $0.519 \pm 0.047$ & $-21.1 \pm 2.17$ \\
\hline 60 & $124.14 \pm 8.29$ & $0.533 \pm 0.076$ & $-20.24 \pm 2.08$ & $112.47 \pm 3.47$ & $0.521 \pm 0.023$ & $-20.6 \pm 2.89$ \\
\hline
\end{tabular}

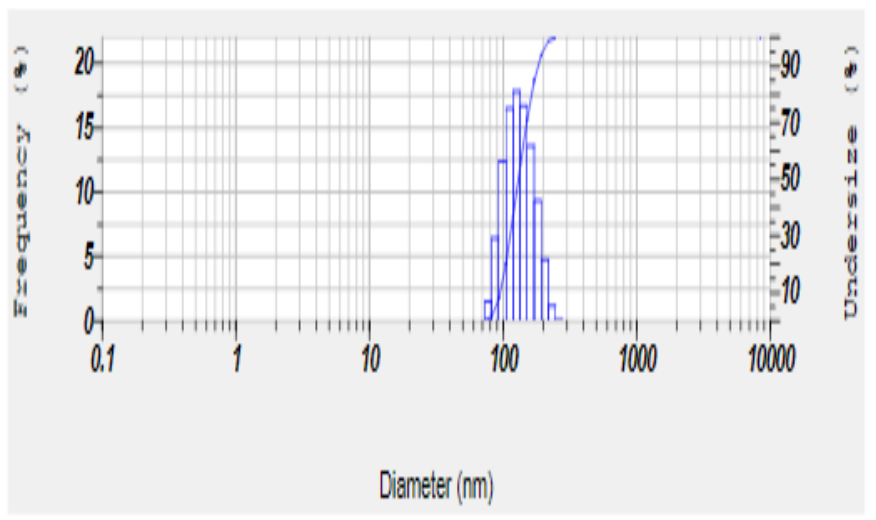

Fig. 4: Particle size analysis of optimized formulation (F6) of Lapatinib SLN

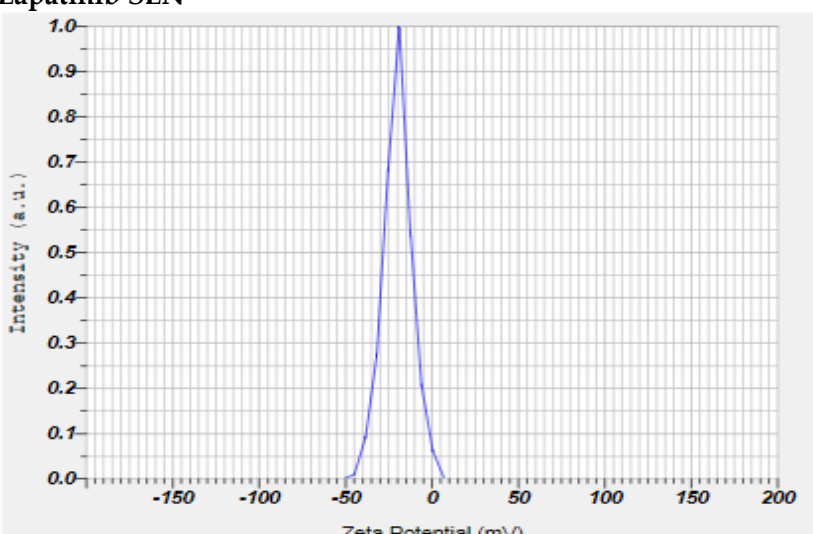

Fig. 5: Zeta potential of the Lapatinib SLN optimized formulation F6

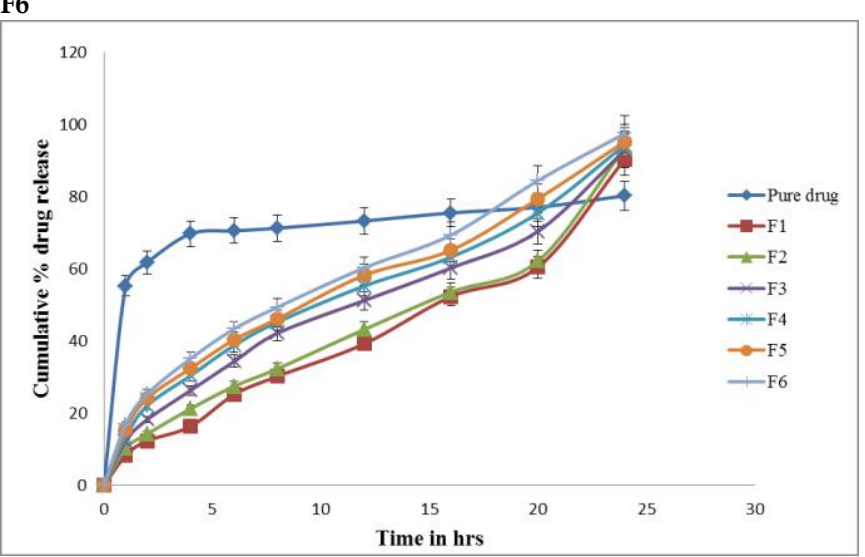

Fig. 6: Cumulative $\%$ drug release from Lapatinib SLNs
The Poly-dispersity index of SLNs was in between 0.398 to 0.731 and it was reduced to narrow range due to increasing concentration of surfactant.

The zeta potential of SLNs varies from -19.9 to -26.3 $\mathrm{mV}$. The results indicate that formulations containing Dynasan-112 exhibited smaller particle sizes and larger PDI, zeta potential values. The formulations comprising Dynasan-116 (F6) exhibited better particle size and zeta potential values in comparison with other formulations.

\section{Stability studies}

Stability studies conducted for 60 days indicated no significant variations in the particle size, PDI, zeta potential, EE and drug release data of the optimized formulation (F6).

The SLNs were successfully formulated for Lapatinib by the process Homogenization and Ultrsonication. These are economically manufactured from Dynasan112, Dynasan-116 and Egg Lecithin etc. The prepared formulations characterized for particle size, PDI, Zeta potential, DSC, scanning electron microscopy, entrapment efficiency and in-vitro drug dissolution studies. Results indicated that increase in the concentration of Lipid content lead to higher entrapment efficiency. A controlled drug release was observed in In-vitro drug dissolution pattern of SLN. Thus, results conclude that the Lapatinib loaded SLNs are effective drug carrier with increased solubility and bioavailability.

\section{REFERENCES}

1. Bargoni A, Cavalli R, Zara GP. Transmucosal transport of tobramycin incorporated in solid lipid nanoparticles (SLN) after duodenal administration to rats. Part II - Tissue distribution. Pharm Res. 2001; 43: 497-502.

2. Freitas C, Müller RH. Effect of light and temperature on zeta potential and physical stability in solid lipid nanoparticles (SLN) dispersions. Int. J. Pharm. 1998; 168:221-229.

3. Cavalli R, Caputo O, Gasco MR. Solid lipospheres of doxorubicin and idarubicin. Int J Pharm. 1993; 89:9-12.

4. Stuchlik M, Zak S. Lipid-based vehicle for oral drug delivery. Biomedical Papers of the Medical Faculty of the University Palacky. 2001; 145(2):17-26. 
Pamu Sandhya et al. / Development and Evaluation of Lapatinib Solid Lipid Nanoparticles

5. Das S, Chaudhury A. Recent advances in lipid nanoparticle formulations with solid matrix for oral drug delivery. AAPS Pharm SciTech. 2011; 12(1):62-76.

6. Rusnak D, Affleck W, Cockerill K, Stubberfield SG, Harris C, Page R, Smith M, Guntrip KJ, Carter SB, Shaw MC. The characterization of novel, dual ErbB-2/EGFR, tyrosine kinase inhibitors: Potential therapy for cancer. Cancer Res. 2001; 61:7196-7203.

7. Konecny GE Pegram MD, Venkatesan N, Finn R, Yang G, Rahmeh M, Untch M, Rusnak DW, Spehar G, Mullin RJ. Activity of the dual kinase inhibitor lapatinib (GW572016) against HER-2-overexpressing and trastuzumab-treated breast cancer cells. Cancer Res. 2006; 66:1630-1639.

8. Higa GM, Abraham J. Lapatinib in the treatment of breast cancer. Expert Review of Anticancer Therapy (Future Drugs). 2007; 7(9): 1183-92.

9. Glaxo Smith Kline (GSK). Glaxo Smith Kline receives marketing authorization in the EU for Tyverb (lapatinib), the first oral targeted therapy for ErbB2-positive breast cancer. Glaxo Smith Kline (GSK) Press release. 2008; 06-12.

10. Venkateshwarlu V, Manjunath K. Preparation, characterization and in vitro release kinetics of clozapine solid lipid nanoparticles. J Control Rel. 2004; 95:627-38.

11. Dudhipala N, Veerabrahma K. Improved anti-hyperlipidemic activity of Rosuvastatin Calcium via lipid nanoparticles: Pharmacokinetic and pharmacodynamic evaluation. European Journal of Pharmaceutics and Biopharmaceutics. 2017; 110:47-57.

12. Singh S, Dobhal AK, Jain A, Pandit JK, Chakraborty S. Formulation and evaluation of solid lipid nanoparticles of a water soluble drug: Zidovudine. Chemical and Pharmaceutical Bulletin. 2010; 58(5):650-655.

13. Fundaro A, Cavalli R, Bargoni A. Non-stealth and stealth solid lipid nanoparticles (SLN) carrying doxorubicin: pharmacokinetics and tissue distribution after IV administration to rats. Pharm Res. 2000; 42: 337-43.

HOW TO CITE THIS ARTICLE: Sandhya P. Development and Evaluation of Lapatinib Solid Lipid Nanoparticles in the Management of Breast Cancer. Int. J. Pharm. Sci. Drug Res. 2019; 11(5): 245-249. DOI: 10.25004/IJPSDR.2019.110515 